\title{
Removal of crystal violet from wastewater using different chitosans and cross-linked derivatives
}

\author{
P. Jassal \& V. Raut \\ Department of Chemistry, SGTB Khalsa College, \\ University of Delhi, India
}

\begin{abstract}
The crab shell chitosan (CSC) and the medium molecular weight chitosan (MMWC) beads are cross-linked with ethylene glycol diglycidyl ether (EGDE) solution to get EGDE-CSC and EGDE-MMWC beads. The adsorption of CSC and MMWC beads at $\mathrm{pH} 2-4$ show the adsorption of crystal violet (CV) was not significantly affected. Langmuir' isotherm study provides an equilibrium parameter $\mathrm{R}_{\mathrm{L}}$, from the linear plots of $\mathrm{C}_{\mathrm{e}} / \mathrm{X}$ versus $\mathrm{C}_{\mathrm{e}}$ for the adsorption of $\mathrm{CV}$ dye on MMWC beads and CSC beads. The adsorption is favourable if $\mathrm{R}_{\mathrm{L}}$ lies within the range, i.e. $0<\mathrm{R}_{\mathrm{L}}<1$. The TGA plots were performed on $\mathrm{CV}$ dye, and $\mathrm{CV}$ was absorbed on the MMWC powder, MMWC bead, and the EGDE-MMWC beads. Degradation takes place in two steps. The thermogravimetric analysis (TGA) of $\mathrm{CV}$ absorbed on MMWC, cross-linked with EGDE show that there is a decrease in the thermal stability of the cross-linked chitosans. Fourier Transform Infrared Spectrometer (FT-IR) gives a band at $1586 \mathrm{~cm}^{-1}$ for $-\mathrm{N}\left(\mathrm{CH}_{3}\right)_{2}$ and aromatic ring stretching $(-\mathrm{C}=\mathrm{C}-)$ clear band at $1363 \mathrm{~cm}^{-1}$ for $\mathrm{CV}$. The IR of pure chitosan shows a broad band at $3433 \mathrm{~cm}^{-1}$ due to $-\mathrm{NH}_{2}$ stretching and $-\mathrm{OH}$ stretching at $1640 \mathrm{~cm}^{-1}$ and the band between 720 and $590 \mathrm{~cm}^{-1}$ shows -OH out-of-plane bend. The CV absorbed on CSC at different time intervals, MMWC powder, beads and $10-20 \%$ cross-linked EGDE-MMWC has also been studied.

Keywords: equilibrium parameter $R_{L}$, thermal stability, cross-linked chitosans, Langmuir' isotherm.
\end{abstract}




\section{Introduction}

Dyes are widely used in industries such as textiles, leather, paper, plastics, etc. to color their final products [1]. Over 100,000 different types of commercially available dyes exist and more than $7 \times 10^{5}$ tons are produced annually $[2,3]$. Dyes are released into wastewaters from various industries, mainly from dye manufacturing, textiles and other fabric-finishing units [4]. A very small amount of dye in water is highly visible and can be toxic to aquatic life [5]. Textile industries release large quantities of aqueous wastes containing dye effluents, which are discharged from the dyeing process with a strong persistent color and high biochemical oxygen demand (BOD) loading, and which are aesthetically and environmentally unacceptable [6]. Most of these dye wastes are highly toxic and also carcinogenic [7]. The discovery of synthetic dyes has overwhelmed the role of natural dyes in society due to their low cost, brighter colors, better resistance toward environmental factors, ease of application, etc. [8]. Dye molecules comprise two components: the chromophores, responsible for producing the color, and the auxochromes which not only supplement the chromophores but also render the molecule soluble in water and give an enhanced affinity toward the fibers $[9,10]$. Crystal violet (CV), the tris [4-(dimethylamine) phenyl] methylium chloride, is used to test bacteria as gram positive or negative and as a fluorescent tracer by physicists. It is one of the most stable carbocations in aqueous solvents [11]. CV has medical use in treating the blood-transfusioninduced Chagas disease, which is noteworthy [12].

Chitosan is derived from chitin, a natural found in the exoskeleton of crustaceans, insects and some fungi [13]. The name chitin is derived from the Greek word "Chiton", meaning a coat of mail, and apparently first used by Bradconnot in 1811 [14]. Chitin, the second most abundant natural polymer in the world, functions as a natural structural polysaccharide. Its estimated production is $10^{10}-10^{12}$ tons per year [15]. Chitosan, a naturally occurring polysaccharide, is a cationic polysaccharide composed of $(\beta-1,4) 2$-amino-2-deoxy-D-glucopyranose, obtained from the alkaline deacetylation of chitin [16]. Chitosan have unique properties such as biodegradability, biocompatibility and bioactivity and have a variety of potential applications in biomedical products, cosmetics and food processing, as metal chelating agents [17].

\section{Experimental method}

\subsection{Material and methods}

Crab shell chitosan (CSC), a with degree of deacetylation, $\geq 75 \%$ and medium molecular weight chitosan (MMWC) powder, were purchased from SigmaAldrich chemicals. Acetic acid (glacial 99-100\%) was procured from E Merk, Worli, Mumbai. Sodium tripolyphosphate (STP) anhydrous, CV dye, and analytical reagents (AR) were supplied by the Loba Chemie laboratory and CHD Laboratory Reagents, New Delhi. The ethylene glycol diglycidyl ether (EGDE) of 
Sigma-Aldrich, $\mathrm{HCl}$ and $\mathrm{NaOH}$ and all the reagents used were of $\mathrm{AR}$ or guaranteed reagents (GR) grade. Double-distilled water was used to prepare all the solutions.

\subsection{Preparation of chitosan beads}

Chitosan beads were prepared by dissolving $3 \mathrm{~g}$ of MMWC powder in $100 \mathrm{ml}$ of $2 \%$ acetic acid solution and $30 \mathrm{ml}$ of double-distilled water was added. The MMWC solution was stirred for 24 hours and after that it was transferred to a burette. The 1\% STP solution was prepared in double-distilled water. $50 \mathrm{ml}$ of $1 \%$ STP solution was taken in a petri dish and kept under the burette of MMWC solution. On carefully releasing the knob of the burette, the chitosan solution comes out in the form of tiny drops. The chitosan solution forms uniform spherical beads as it comes in contact with the STP solution in the petri dish. The beads were kept in the STP solution overnight. The wet chitosan beads were extensively rinsed with double-distilled water and finally air dried to remove the water from the pore structure, hereafter, called the MMWC beads. The beads of the CSC powder were prepared in the same way (Figure 1).

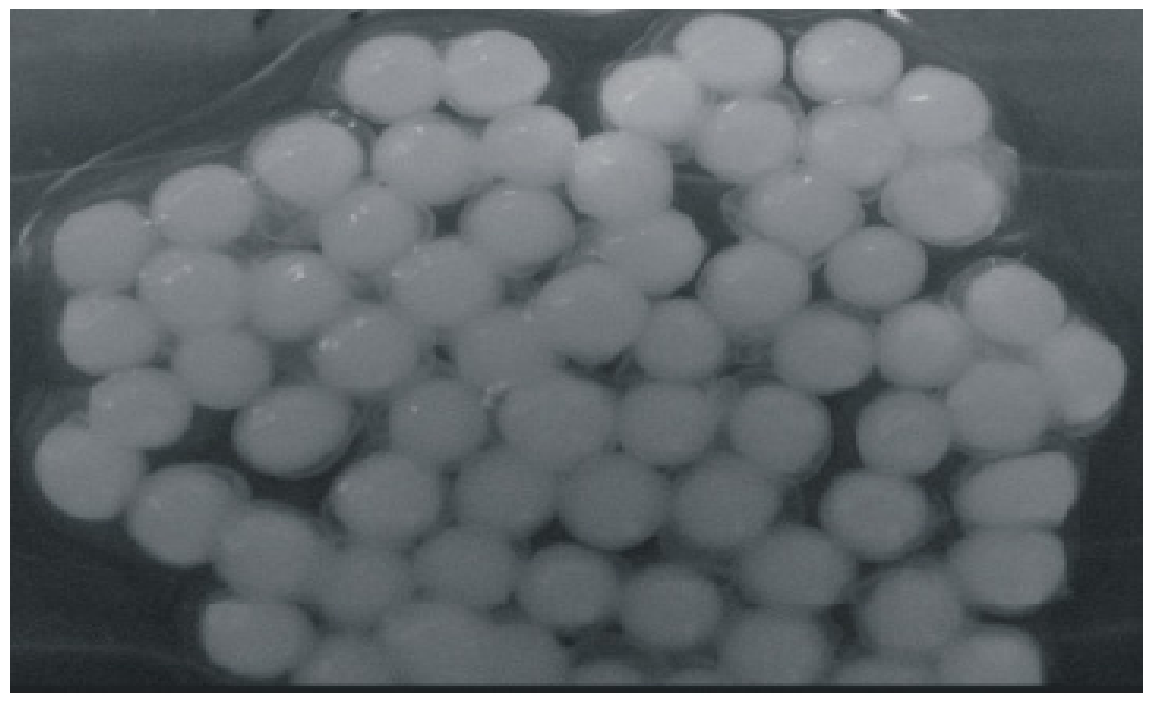

Figure 1: Beads of CSC powder prepared in the laboratory.

\subsection{Preparation of cross-linked chitosan beads}

EGDE beads were obtained using a procedure described by Zeng and Ruckenstein [18]. Freshly prepared wet chitosan beads of MMWC or CSC were kept in 5\% of the EGDE solution and stirred for 3 hours at a temperature between 40 and $50^{\circ} \mathrm{C}$. To filter the beads, they were washed thoroughly with double-distilled water to remove unreacted EGDE solution and then air dried. The newly formed beads are called EGDE-MMWC or EGDE-CSC beads. 


\subsection{Adsorption experiment}

A stock solution of $\mathrm{CV}$ was prepared by dissolving $0.0408 \mathrm{~g}$ of $\mathrm{CV}$ dye in $1000 \mathrm{ml}$ of double-distilled water. The batch adsorption experiment was conducted by taking $50 \mathrm{ml}$ of CV solution in a $100 \mathrm{ml}$ beaker and $0.1 \mathrm{~g}$ of MMWC or CSC beads were added to the $\mathrm{CV}$ solution while stirring the solution continuously. The experiment was carried out at different $\mathrm{pH}$ values, using either $0.1 \mathrm{~N} \mathrm{HCl}$ or $0.1 \mathrm{~N} \mathrm{NaOH}$. The MMWC or CSC beads were equilibrated at a particular $\mathrm{pH}$ for 30 minutes of contact time with continuous stirring. The samples were taken out at regular intervals of time and samples were diluted and analyzed on the UV-Visible spectrophotometer of an Analytical Jena Specord 250. The absorbance of the CV was studied in the range of 400-600 nm at $\lambda_{\max } 591 \mathrm{~nm}$. The amount of dye adsorbed per unit mass of chitosan (mg g-1) can be calculated, as shown in eqn. (1):

$$
\mathrm{Q}=\left[\left(\mathrm{C}_{\mathrm{o}}-\mathrm{C}_{\mathrm{e}}\right) / \mathrm{V}\right] / \mathrm{m}
$$

where $\mathrm{Q}$ is the amount of dye adsorbed per gram adsorbent $\left(\mathrm{mg} \mathrm{g}^{-1}\right), \mathrm{C}_{\mathrm{o}}$ concentration is the initial dye concentration $\left(\mathrm{mg} \mathrm{L}^{-1}\right), \mathrm{C}_{\mathrm{e}}$ is the concentration of dye at equilibrium with solid phase $\left(\mathrm{mg} \mathrm{g}^{-1}\right), \mathrm{m}$ is the mass of chitosan and $\mathrm{V}$ is the volume of solution used.

\section{Results and discussion}

\subsection{Effects of $\mathrm{pH}$}

The adsorption of CV by the CSC and MMWC beads at $\mathrm{pH}$ 2, 3 and 4 was studied with different time intervals. It was found that the adsorption amount of $\mathrm{CV}$ was not significantly affected by $\mathrm{pH} 2-4$, due to the ionic structure of the dye. As the $\mathrm{pH}$ of $\mathrm{CV}$ solution decreased, the number of positively charged surface sites increased, which did not favor the adsorption of positively charged dye cations due to electrostatic repulsion. The lower levels of adsorption of $\mathrm{CV}$ by the chitosans is due to the presence of excess $\mathrm{H}^{+}$ions [19].

\subsection{Adsorption isotherm: Langmuir isotherm}

Adsorption experiments involve the adsorption of adsorbate on adsorbent and determine the adsorption capacity and its selectivity. They provide important information on how the adsorbate molecules are distributed between the liquid phase and the solid phase when the adsorption process reaches equilibrium state. The experiment was performed on the MMWC beads at $\mathrm{pH} 2,3$ and 4, and for the $\mathrm{CSC}$ beads, at $\mathrm{pH}$ 4. The adsorption behavior can be described with the Langmuir adsorption eqn. (2).

$$
\mathrm{C}_{\mathrm{e}} / \mathrm{X}=\left[\mathrm{C}_{\mathrm{e}} / \mathrm{X}_{\max }+1 / \mathrm{X}_{\max } \cdot \mathrm{b}\right]
$$


In equation (2), $\mathrm{C}_{\mathrm{e}}$ is the equilibrium or final concentration of $\mathrm{CV}$ ions (ppm), $\mathrm{X}$ is the amount of $\mathrm{CV}$ ions adsorbed per unit weight of chitosan beads at equilibrium concentration $\left(\mathrm{ml} \mathrm{mg} \mathrm{mg}^{-1}\right), \mathrm{X}_{\max }$ is the maximum adsorption at monolayer coverage $\left(\mathrm{mg} \mathrm{g}^{-1}\right)$ and $\mathrm{b}$ is the Langmuir adsorption equilibrium constant $\left(\mathrm{ml} \mathrm{mg}^{-1}\right)$ and is a measure of the energy of the adsorption.

A linearized plot of $\mathrm{C}_{\mathrm{e}} / \mathrm{X}$ versus $\mathrm{C}_{\mathrm{e}}$ (Figure 2) is utilized to calculate the $\mathrm{X}_{\max }$ and $b$ values.

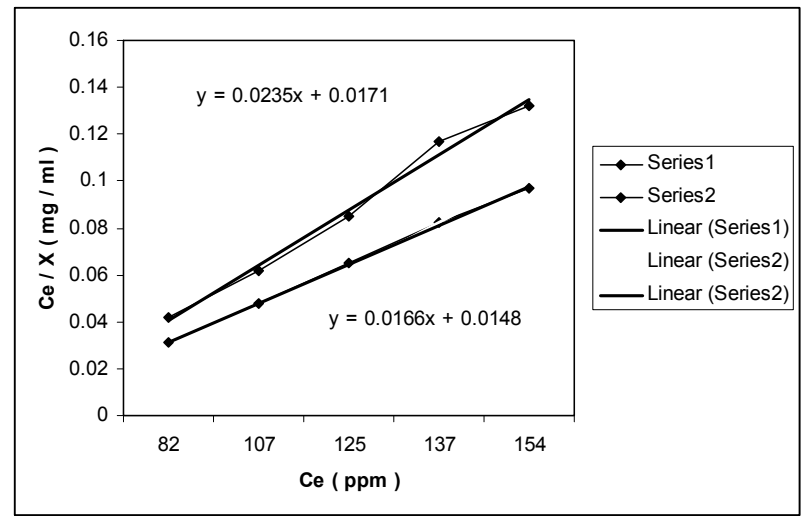

Figure 2: Linear plots of $\mathrm{C}_{\mathrm{e}} / \mathrm{X}$ vs $\mathrm{C}_{\mathrm{e}}$ to calculate $\mathrm{R}_{\mathrm{L}}$ values.

Table 1: $\mathrm{R}_{\mathrm{L}}$ values calculated from Langmuir equation.

\begin{tabular}{|l|c|c|c|}
\hline \multirow{2}{*}{ Adsorption of CV on: } & \multicolumn{2}{|c|}{ Adsorption constants } & \multirow{2}{*}{$\mathrm{R}_{\mathrm{L}}$ values } \\
\cline { 2 - 3 } & $\mathrm{X}_{\max }(\mathrm{mg} / \mathrm{g})$ & $\mathrm{b}(\mathrm{ml} / \mathrm{mg})$ & \\
\hline Chitosan (CSC) beads & 79.6 & 6.2 & 0.17 \\
\hline MMWC beads & 21.5 & 1.7 & 0.12 \\
\hline
\end{tabular}

This result was due to the positive charge of the basic dye that creates strong columbic repulsions between chitosan and the basic dye, which explains the lower adsorption capacity [20]. The hydroxyl group $(-\mathrm{OH})$ in chitosan could adsorb the basic dye via covalent and hydrogen bonding, similar to the adsorption mechanism of cellulose polymers with reactive dye [21]. It shows that the Langmuir equation fits best for $\mathrm{CV}$ ion adsorption on the chitosan beads under the concentration range studied (correlation coefficient, $r>0.99$ ). The effect of the isotherm shape is approached with a view to predicating if an adsorption system is "favourable" or "unfavourable". The essential features of a Langmuir isotherm can be expressed in terms of the dimensionless constant separation factor or equilibrium parameter, $R_{L}$, which is defined by eqn. (3).

$$
\mathrm{R}_{\mathrm{L}}=1 /\left(1+\mathrm{b} \cdot \mathrm{C}_{\mathrm{o}}\right)
$$


where $\mathrm{C}_{\mathrm{o}}$ is the initial $\mathrm{CV}$ concentration (ppm) and b is Langmuir constant ( $\mathrm{ml}$ $\left.\mathrm{mg}^{-1}\right)$. The $\mathrm{R}_{\mathrm{L}}$ values, $\left(0<\mathrm{R}_{\mathrm{L}}<1\right)$ showing that the favourable adsorption on chitosan beads takes place, are given in Table 1 , along with the $X_{\max }$ and $b$ values. If the value of $R_{L}>1$, then this shows the unfavourable condition for adsorption and $\mathrm{R}_{\mathrm{L}}=0$ represents irreversible adsorption.

\subsection{Thermogravimetric analysis (TGA)}

A Perkin Elmer, Diamond TGA/DTA were used for the thermogravimetric analysis of the blended samples. A small amount (1-10 mg) of samples was taken for the analysis and the samples were heated from 25 to $1000^{\circ} \mathrm{C}$ at a rate of $10^{\circ} \mathrm{C} / \mathrm{min}$ in the atmosphere of nitrogen.

The experiment was performed on $\mathrm{CV}$ dye, and $\mathrm{CV}$ absorbed on MMWC powder, MMWC bead, and EGDE-MMWC bead. The TGA in Figure 3 shows that the degradation takes place in two steps. Several literature reports of changes in the thermal degradation of chitosan and cross-linked chitosan were interpreted in different ways. According to Neto et al. 2005 [22], the cross-linking of chitosan decreases the thermal stability. Our experimental results are presented in Table 2, which support the fact that chemical modification generally leads to decrease in the thermal stability of chitosan.

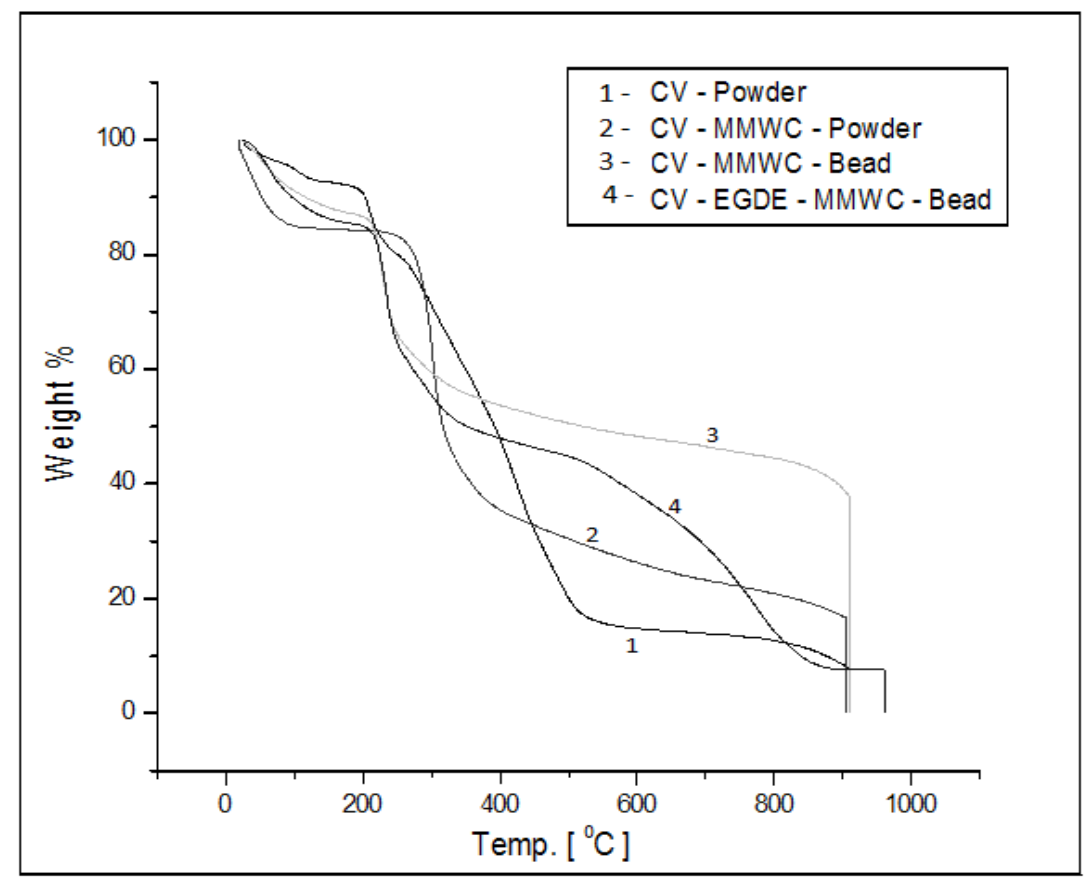

Figure 3: TGA of CV powder and CV absorbed on MMWC powder, beads and cross-linked MMWC (EGDE-MMWC). 
Table 2: TGA of CV, CV adsorbed on MMWC chitosan and cross-linked beads.

\begin{tabular}{|l|l|c|c|c|c|c|}
\hline S. No & $\begin{array}{l}\text { CV-powder, } \\
\text { chitosan and } \\
\text { cross-linked } \\
\text { beads }\end{array}$ & \multicolumn{2}{|c|}{ First stage } & \multicolumn{2}{|c|}{ Second stage } & $\begin{array}{l}\text { Remaining } \\
\text { weight \% at } \\
1000^{\circ} \mathrm{C}\end{array}$ \\
\cline { 2 - 7 } & $\mathrm{T}\left({ }^{\circ} \mathrm{C}\right)$ & $\begin{array}{l}\text { Weight } \\
\text { loss \% }\end{array}$ & $\mathrm{T}\left({ }^{\circ} \mathrm{C}\right)$ & $\begin{array}{l}\text { Weight } \\
\text { loss \% }\end{array}$ & \\
\hline 1. & CV-powder & 184 & 08 & 907 & 84 & 08 \\
\hline 2. & $\begin{array}{l}\text { CV-MMWC } \\
\text { powder }\end{array}$ & 213 & 17 & 898 & 66 & 17 \\
\hline 3. & $\begin{array}{l}\text { CV- } \\
\text { MMWC- } \\
\text { bead }\end{array}$ & 201 & 14 & 908 & 48 & 38 \\
\hline 4. & $\begin{array}{l}\text { CV-EGDE- } \\
\text { MMWC- } \\
\text { bead }\end{array}$ & 202 & 15 & 888 & 78 & 07 \\
\hline
\end{tabular}

The pure CV powder first degraded at a temperature of $184^{\circ} \mathrm{C}$ with $8 \%$ loss and the second stage degradation occurred at $907^{\circ} \mathrm{C}$ with $84 \%$ loss; the remaining amount of product was $8 \%$ with a total loss of $92 \%$. CV absorbed on MMWC powder showed the first step degradation at $213^{\circ} \mathrm{C}$ with $17 \%$ loss and second step degradation at $898^{\circ} \mathrm{C}$ with $66 \%$ loss; the remaining product was $17 \%$ with a total loss of $83 \%$. The $\mathrm{CV}$ absorbed on the MMWC beads shows good thermal stability; it started degradation at $201{ }^{\circ} \mathrm{C}$ with $14 \%$ loss and second stage degradation at $908^{\circ} \mathrm{C}$ with $62 \%$ loss, and the remaining product was $38 \%$, with a total loss of $62 \%$. CV absorbed on cross-linked MMWC (EGDE-MMWC) showed first step degradation at $202^{\circ} \mathrm{C}$ with $15 \%$ loss and second step degradation at $888^{\circ} \mathrm{C}$, with $78 \%$ loss; the remaining product was $7 \%$ and the total loss of polymer was $93 \%$. Thus, these results help correlate the decrease of thermal stability in cross-linked chitosans.

\subsection{IR spectrum}

Infrared spectra were recorded on an FT-IR spectrum RXI spectrophotometer, with a resolution of $4 \mathrm{~cm}^{-1}$ with 16 scans in the range of $4000-500 \mathrm{~cm}^{-1}$. The powder samples were thoroughly ground with exhaustively dried $\mathrm{KBr}$ and discs were prepared by compression under a vacuum. The film was investigated using the FT-IR technique. This experiment was performed on different chitosan CSC and MMWC powders, beads, and chitosan-dye complexes.

The FT-IR spectrum of CV can be classified into two groups corresponding to the vibrational modes of the benzene ring system and those substituted groups $\mathrm{N}\left(\mathrm{CH}_{3}\right)_{2}$. The band at $1586 \mathrm{~cm}^{-1}$ shows the aromatic ring stretching $(\mathrm{C}=\mathrm{C}-\mathrm{C})$, $1363 \mathrm{~cm}^{-1}$ shows the sharp peak of aromatic tertiary amine, $-\mathrm{N}(\mathrm{CH} 3)_{2}$, the short peak at $1298 \mathrm{~cm}^{-1}$ of $\mathrm{C}-\mathrm{H}$ in plane bend, and the band between 900 and $670 \mathrm{~cm}^{-1}$ shows the aromatic $\mathrm{C}-\mathrm{H}$ out of plane bend. The IR of pure chitosan shows a broad band at $3433 \mathrm{~cm}^{-1}$ due to $-\mathrm{NH}_{2}$ stretching and $-\mathrm{OH}$ stretching peak at $1640 \mathrm{~cm}^{-1}$ 
and the band between 720 and $590 \mathrm{~cm}^{-1}$ shows $-\mathrm{OH}$ out-of-plane bend. The $\mathrm{CV}$ absorbed on different CSC and MMWC chitosans and the intensity of CV was reduced on the respective chitosan.

The band at $1630 \mathrm{~cm}^{-1}$ shows the aryl substitution $(\mathrm{C}=\mathrm{C})$ and the sharp band in $1370-1365 \mathrm{~cm}^{-1}$ shows the dimethyl substitution.

$\mathrm{CV}$ absorbed on CSC at different time intervals is shown in Figure 4 and the $\mathrm{CV}$ absorbed on the MMWC powder, beads and $10-20 \%$ cross-linked EGDEMMWC is presented in Figure 5.

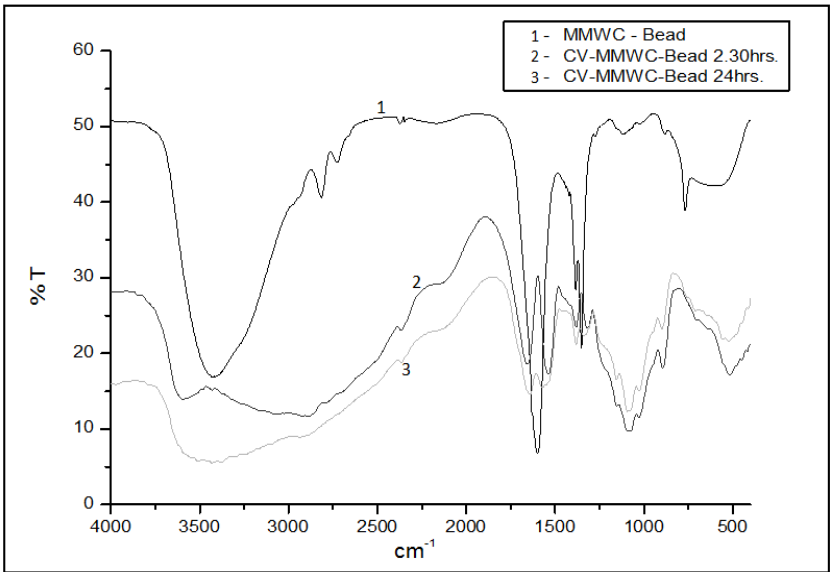

Figure 4: IR spectrums of MMWC bead and CV absorbed on MMWC bead at different time intervals.

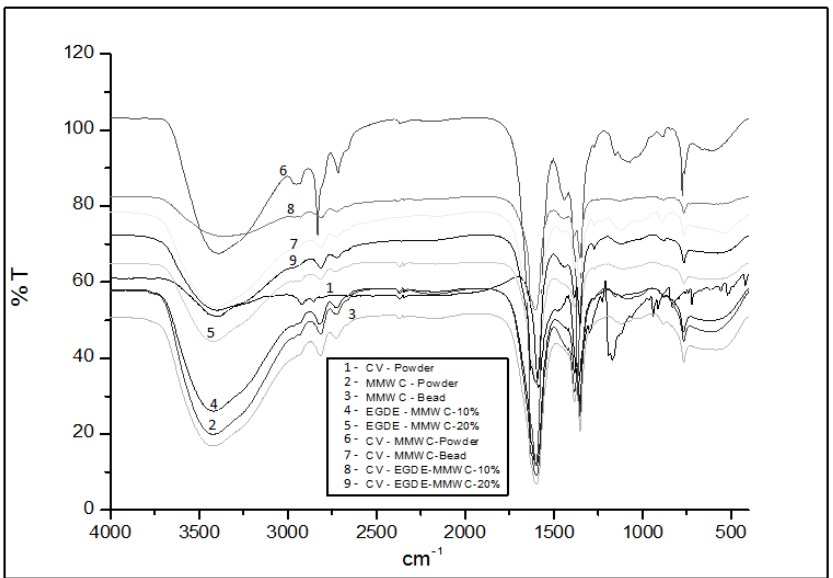

Figure 5: IR spectrums of MMWC powder, beads, and $10-20 \%$ cross-linked MMWC beads (EGDE-MMWC) and CV absorbed on MMWC powder, beads, and $10-20 \%$ cross-linked beads. 


\section{References}

[1] Ming-Shen, C. \& Hsing Y. Li., Equilibrium and kinetic modelling of adsorption of reactive dye on cross-linked chitosan beads. Journal of Hazardous Materials, B93, pp. 233-248, 2002.

[2] Pearce, C.I., Lloyd, J.R. \& Guthrie, J.T., The removal of colour from textile wastewater using whole bacterial cells: a review, Dyes and Pigments, 58, pp. 179-196, 2003.

[3] McMullan, G., Meehan, C., Conneely, A., Kirby, T. N., Robinson, N. P., Banat, I. M., Marchant, R. \& Smyth, W. F., Microbial decolourisation and degradation of textile dyes. Applied Microbiology and Biotechnology, 56, pp. 81-87, 2001.

[4] Hasan, M., Ahmad, A. L., \& Hameed, B. H., Adsorption of reactive dye onto cross-linked chitosan/oil palm ash composite beads. Chemical Engineering Journal, 136, pp. 164-172, 2008.

[5] Chiou, M.S. \& Li, H.Y., Adsorption behavior of reactive dye in aqueous solution on chemical cross-linked chitosan beads. Chemosphere, 50, pp. 1095-1105, 2003.

[6] Hu, Z.G., Zhang, J., Chan, W. L. \& Szeto, Y.S., The sorption of acid dye onto chitosan nanoparticles, Polymer, 47, pp. 5838-5842, 2006.

[7] Vandevivere, P. C., Bianchi, R. \& Verstraete, W. Treatment and reuse of wastewater from the textile wet-processing Industry: Review of emerging technologies. Journal of Chemical Technology and Biotechnology, 72, pp. 289-302, 1998.

[8] Wan Ngaha, W.S., Teonga, L.C., Hanafiah, M.A.K.M., Adsorption of dyes and heavy metal ions by chitosan composites: A review, Carbohydrate Polymers. 83, pp. 1446-1456, 2011.

[9] Gupta, V. K. \& Suhas, Application of low-cost adsorbents for dye removal: A review. Journal of Environmental Management, 90, pp. 2313-2342, 2009.

[10] Sudipta, C., Lee, M.W. \& Seung, W.H, Adsorption of congo red by chitosan hydrogel beads impregnated with carbon nanotubes. Bioresource Technology. 101, pp. 1800-1806, 2010.

[11] Claire, L., Rodolphe, A., Michel, B., Philippe, D., Julien, G. \& Daniel, S., Microsolvation Effects on the Optical Properties of Crystal Violet. Chemistry A European Journal. 14, pp. 7351-7357, 2008.

[12] Carla, S., Kerlley, P., Mauricio, S. \& Guilherme, L., Solvent and concentration effects on the visible spectra of tripara-dialkylaminosubstituted triarylmethane dyes in liquid solutions., Spectrochimica Acta Part A, 58, pp. 2971-2982, 2002.

[13] Ling, S.L.Y., Yee, C.Y. \& Eng, H. S., Removal of a cationic dye using deacetylated chitin (chitosan), Journal of Applied Sciences, 11, pp. 14451448, 2011.

[14] Shahidi, F., Kamil, J., Arachchi V. \& Jeon, Y. J., Food applications of chitin and chitosans, Trends in Food Science \& Technology, 10, pp. 37-51, 1999. 
[15] Kumirska, J., Czerwicka, M., Kaczyński, Z., Bychowska, A., Brzozowski, K., Thöming, J. \& Stepnowski, P., Application of spectroscopic methods for structural analysis of chitin and chitosan. Marine Drugs, pp. 8, 1567$1636,2010$.

[16] Esam A, El-hefian., Mohamed, M. N. \& Abdul, H. Y., Chitosan physical forms: A short review. Australian Journal of Basic and Applied Sciences, 5, pp. 670-677, 2011.

[17] Arh, H.C., Sheng, C. L., Chia, Y.C. \& Chia, Y. C., Comparative adsorption of $\mathrm{Cu}$ (II), $\mathrm{Zn}$ (II), and $\mathrm{Pb}$ (II) ions in aqueous solution on the cross-linked chitosan with epichlorohydrin. Journal of Hazardous Materials, 154, pp. 184-191, 2008.

[18] Zeng, X. \& Ruckenstein, E., Cross-linked macroporous chitosan anionexchange membranes for protein separations. Journal of Membrane Science, 148, pp. 195-205, 1998.

[19] Pandian. G.V., Jayaraj. R., Srinivasan Anbu, P., Deva, P. M. P., \& Selvamathan, S., Adsorption efficiency of crystal violet dye onto sludge (effluent) obtained from caustic industries. International Journal of Research in Chemistry and Environment, 2, pp. 265-269, 2012.

[20] Kyzas, G.Z. \& Lazaridis, N.K., Reactive and basic dyes removal by sorption onto chitosan derivatives. Journal of Colloid and Interface Science, 331, pp. 32-39, 2009.

[21] Sakkayawong, N., Thiravetyan, P. \& Nakbanpote, W., Adsorption mechanism of synthetic reactive dye wastewater by chitosan. Journal of Colloid and Interface Science, 286, pp. 36-42. 2005.

[22] Neto, C.G.T., Giacometti, J.A., Job, A. E., Ferreira, F. C., Fonseca, J. L. C. \& Pereira, M. R., Thermal analysis of chitosan based networks. Carbohydrate Polymers, 62, pp. 97-103, 2005. 